\title{
McGill
}

\section{Behavioural responses of feral and domestic guppies (Poecilia reticulata) to predators and their cues}

William T. Swaney, Maria J. Cabrera-Alvarez, and Simon M. Reader

Behavioural Processes Volume 118, September 2015, Pages 42-46

doi: 10.1016/j.beproc.2015.05.010

http://www.sciencedirect.com/science/article/pii/S0376635715001333

Copyright 2015 Elsevier B. V. This postprint provided under the terms of a Creative Commons Attribution NonCommerical NoDerivatives license (CC BY-NC-ND). 


\section{Behavioural responses of feral and domestic guppies (Poecilia reticulata) to predators and their cues}

William T. Swaney, Maria J. Cabrera-Álvarez, and Simon M. Reader 


\section{Introduction}

Predation is a major driver of variation across taxa, influencing behaviours that may lessen predation risk, such as social grouping (Hass and Valenzuela, 2002; Magurran, 1990a; Quinn and Cresswell, 2006) and vigilance (Forslund, 1993; Lung and Childress, 2007). However, these behaviours can also carry costs. For example, grouping may increase competition for resources or exposure to parasites (Krause and Ruxton, 2002). Thus, antipredator behaviours are expected to vary across populations experiencing different levels of predation.

Studies of wild guppies (Poecilia reticulata) on the Caribbean island of Trinidad have shown that populations under high levels of predation form tighter shoals (Magurran and Seghers, 1991; Seghers, 1974); engage in less risky predator inspection (Magurran and Seghers, 1990, 1994) and exhibit changes in sensitivity to conspecific alarm cues (Brown et al., 2009). While extensive study of wild guppies has provided strong evidence for evolved adaptation to predation in Trinidad, the guppy is also an important invasive species affecting local ecology, with feral populations identified in 60 countries across six continents (Froese and Pauly, 2012). These feral populations are often derived from inbred ornamental guppies (Lindholm et al., 2005), artificially selected for traits that may not be adaptive in the wild (Huntingford, 2004). Their success in novel habitats with allopatric predators suggests that domestic guppies retain traits that are adaptive in new environments (Deacon et al., 2011) or have sufficient genetic diversity to adapt to new environmental challenges.

We examined the influence of feralisation and predation on the behaviour of guppies from Burgers' Zoo in Arnhem, the Netherlands. The zoo contains a 120 m3 manatee (Trichechus manatus) pool which also houses a feral population of guppies, derived from an initial introduction of mixed-strain domestic guppies released by a zoo visitor in 1989, and subsequently left untended. The release was observed by zoo curators, who estimate that it consisted of approximately 100 individuals (Max Janse, Burgers' Zoo curator, personal communication, 2015). The population has subsequently expanded considerably and is estimated to number well over 100,00o guppies (Max Janse, personal communication; Albers, 
2000). These now-feralized guppies forage on plentiful manatee food and faeces, but are subject to predation from three resident African darters (Anhinga rufa) which dive regularly each day for guppies (personal observation) and have been reported to eat up to 1000 guppies each per day (Albers, 2000). The feral guppies resemble wild guppies in appearance and have lost the bright colours and extravagant tails typical of domestic guppies (Fig. 1A). A previous study examined body colouration in these fish, and anecdotally reported dense shoaling among these feral guppies (Albers, 2000). We compared this feral population with mixed-strain domestic guppies akin to the ancestral founders and measured predationlinked behaviours: shoaling, predator inspection behaviour, alarm substance sensitivity, and boldness/exploration. We predicted the feral guppies would shoal more, inspect predators more cautiously, be more sensitive to alarm substance, and be less bold and exploratory as a consequence of feralisation and adaptation to predation.

\section{Materials and methods}

\subsection{Subjects and housing}

Nineteen domestic and 19 feral male guppies were used as experimental subjects, with a further 14 domestic and 14 feral males used either as shoaling companions or for alarm substance extraction. Domestic guppies were from a mixed strain population of approximately 1400 fish, first established in 2003 within the Utrecht University Biology aquarium and based on a founder population of approximately 480 domestic guppies purchased from two commercial suppliers (Ruinemans, Montfoort and Ruisbroek, Maassluis, both The Netherlands). Feral guppies were caught with dip nets from the manatee pool at Burgers' Zoo. Feral guppies were sampled in November 2009, four months before the study, and rehoused in our aquarium. Thus, the feral guppies had both an evolutionary history and direct experience of predation. Given an estimate of two generations per year (Magurran, 2005; Reznick et al., 1997), the domestic guppies are estimated to have bred for 10-15 generations in the Utrecht 
aquarium and the feral guppies for $35-45$ generations at Burgers' Zoo. Feral guppies were treated to remove ectoparasites after capture by 15 min immersion in $2.5 \%$ salt solution as a precautionary measure. Domestic guppies had brighter and more varied colouration patterns than feral guppies, but subjects of each population were similarly sized. Two male red rainbowfish (Glossolepsis incisus) from our aquarium were used as potential predators as they represented a novel, allopatric threat to both domestic and feral guppies. Two weeks before the study, all experimental animals were moved to our experimental laboratory. Laboratory lights were on from 08:00 to 20:00. Fish were housed separately by population/species in $80 \times 50 \times 40 \mathrm{~cm}$ tanks except for shoaling companion guppies which were housed in a $90 \times 50 \times 25 \mathrm{~cm}$ tank, with domestic and feral guppies separated by an opaque partition. Tanks contained gravel, plastic plants and terracotta pots, and were filtered and heated to $26 \pm 1{ }^{\circ} \mathrm{C}$. Fish were fed TetraMin flake food (Tetra, Germany) daily and fresh bloodworm (Chironomidae larvae) three times a week.

\subsection{Experimental procedures}

Subjects were tested for: (i) boldness and exploration, (ii) responses to alarm substance, and (iii) shoaling and predator inspection, with 3-7 days between tests. Test order was consistent so any carry-over effects from each test were the same across individuals. Housing tanks were divided with plastic partitions to create separate areas for subjects after testing. On test days, fish were fed at the conclusion of testing. Some fish were excluded from tests due to illness or for methodological reasons: 19 guppies per group were used in boldness/exploration tests, 17 guppies per group in alarm substance response tests, and 17 domestic and 15 feral guppies in shoaling and predator inspection tests.

\subsection{Boldness and exploration}

The test tank (Fig. 1B) consisted of a sheltered area with gravel, plastic plants and a terracotta pot, and a bare, brightly lit exposed area, which also contained a suspended opaque partition creating a novel hidden area not visible 
from the sheltered area. Notional boundaries of these areas and the upper and lower halves of the tank were marked on the front of the tank. At test, individual subjects were released into the sheltered area and behaviour recorded for $10 \mathrm{~min}$.

Latencies to enter exposed and hidden areas were analysed by WilcoxonGehan survival test (subjects that did not enter were assigned the maximum latency of $600 \mathrm{~s}$ ). Time in the exposed area data were log transformed and analysed by independentttest, time in the hidden area was analysed by MannWhitney U-test. Activity was assessed by analysing number of transitions between tank quadrants by independent $t$ test.

\subsection{Alarm substance responses}

Mixed-population alarm substance was prepared each test day following established protocols (Brown and Godin, 1999; Brown et al., 2009): a feral and a domestic male guppy were euthanized in ice water and skin and skeletal muscle homogenized with $5 \mathrm{O} \mathrm{l}$ ddH2O, then filtered through glass wool with ddH2O to a final volume of $100 \mathrm{ml}$, which was kept on ice.

Tests were conducted in a $40 \times 25 \times 25 \mathrm{~cm}$ tank containing $20 \mathrm{~cm}$ depth of water and covered on three sides with white plastic. After $2 \mathrm{~min}$ for the subject to habituate, $4 \mathrm{ml}$ of ddH2O was added with a pipette to start the 20 min test. Ten minutes later, $4 \mathrm{ml}$ of alarm substance solution was added. Tested subjects were placed in a holding tank to prevent interaction with untested subjects, then moved to the 'tested' division of their home tanks at the end of each day. The test tank was cleaned and refilled before each test. Time immobile (freezing) and distance swum were analysed by repeated measures ANOVA, with experimental phase (before and after addition of alarm substance) as the repeated factor and population as the independent factor. Freezing data were log transformed before analysis.

\subsection{Shoaling and predator inspection behaviour}

The test tank (Fig. 1C) was lined with gravel and divided with plastic partitions into left (shoal), central (subject) and right (predator) sections. The transparent left partition was one-way glass so the shoal could not see the 
predator or subject (Mathis et al., 1996). The right partition consisted of an impermeable silicone-sealed transparent partition and a removable opaque partition. The shoal section was lit with a $3 \mathrm{~W}$ LED spotlight to ensure the effectiveness of the one-way glass. Two interlocked plastic cups with matching 3 $\mathrm{cm}$ diameter holes were suspended in the subject section, and a shoaling zone adjacent to the companion shoal was marked on the front of the tank, $6 \mathrm{~cm}$ (2 body lengths) from the left partition.

On each test day, 5 same-population companion fish were placed in the shoal section and a red rainbowfish was placed in the predator section. A subject was placed in the suspended cups, with the holes misaligned. After 2 min habituation, the holes were aligned and when the subject exited, the 20 min test began. After $10 \mathrm{~min}$, the opaque partition was removed to reveal the red rainbowfish. We recorded time spent in the shoaling zone and number of predator inspection bouts by each subject over the whole test. At the end of each day, the red rainbowfish and shoaling companion fish were returned to their home tanks. Populations were tested on alternate days to balance test order. Shoaling time data were square root transformed and analysed by repeated measures ANOVA, with experimental phase (before and after the predator was revealed) as the repeated factor and population as the independent factor. Frequency of predator inspection was analysed by independent samples $t$ test.

\subsection{Correlations between anti-predator behaviours}

Relationships between responses to predation cues (the potential predator or alarm cues) were analysed by correlation of behavioural difference scores. A single measure was calculated for the behaviours modulated by exposure to predation cues (shoaling duration, number of predator inspection bouts and freezing duration) by subtracting pre-exposure performance from postexposure performance. These three difference scores were then analysed by Pearson's correlations. Shoaling data difference scores were log transformed prior to analysis. 


\subsection{Analysis}

Tests were videoed using a Logitech Pro 9000 webcam and VirtualDub video capture software. Boldness and exploration tests, and shoaling and predator inspection tests were scored with JWatcher 1.o. Alarm substance tests were analysed with Ethovision XT (Noldus Information Technology, Netherlands). Statistical analyses were conducted with IBM SPSS Statistics 20.

\subsection{Ethics statement}

All procedures were carried out in accordance with Dutch law and approved by the Utrecht animal experimentation commission (Dierexperimentencommissie Utrecht) under licence 2010.I.03.036.

\section{$\underline{\text { 3. Results }}$}

\subsection{Boldness and exploration}

Feral and domestic guppies did not significantly differ in their latency to enter the exposed area (Wilcoxon-Gehan statistic $=0.10, \mathrm{df}=1, \mathrm{P}=0.92$ ) or total time in the exposed area ( $\mathrm{t}$ test, $\mathrm{t} 36=0.70, \mathrm{P}=0.49$ ). There was a nonsignificant trend for feral guppies to enter the hidden area faster (WilcoxonGehan statistic $=3.30, \mathrm{df}=1, \mathrm{P}=0.069$, Fig. $2 \mathrm{~A}$ ) and to spend more time in the hidden area (Mann-Whitney $\mathrm{U}$ test, $\mathrm{U}=240, \mathrm{~N}=19$ per group, $\mathrm{P}=0.085$; Fig. 2B). Populations did not significantly differ in number of transitions between quadrants ( $\mathrm{t}$ test, $\mathrm{t} 36=0.43, \mathrm{P}=0.67$ ).

Subjects responded differently to the sheltered and exposed areas, spending significantly less time in the exposed area than would be expected by chance (one-sample $\mathrm{t}$ test, $\mathrm{t} 37=-2.63, \mathrm{P}=0.012$ ). Similarly, subjects spent significantly less time in the hidden area after entering the exposed area than would be expected by chance (one-sample Wilcoxon signed rank test, $\mathrm{W}=18 \mathrm{o}, \mathrm{N}$ $=38, \mathrm{P}=0.005$; chance expectations were based on the relative volume of each area). This avoidance of the exposed and hidden areas supports the use of time 
spent in these areas as combined measures of boldness and exploration (sensu Réale et al., 2007).

\subsection{Alarm substance responses}

Alarm substance significantly increased freezing (repeated measures ANOVA, F1,32 = 44.98, $\mathrm{P}<$ 0.001, Fig. $2 \mathrm{C})$, and decreased distance swum (F1,32 $=7.79, \mathrm{P}=0.009$ ), but these responses did not differ significantly between populations, nor were there significant interactions between population and alarm substance exposure (all: F1,32 $\leq 0.74, \mathrm{P} \geq 0.40$ ).

\subsection{Shoaling and predator inspection behaviour}

Exposure to the red rainbowfish significantly increased shoaling (repeated measures ANOVA, F1,30 = 14.00, $\mathrm{P}=0.001$ ), and feral guppies spent longer shoaling than domestic guppies $(\mathrm{F} 1,30=10.71, \mathrm{P}=0.003)$. There was no significant interaction between population and predator exposure $(\mathrm{F} 1,30=0.86$, $\mathrm{P}=0.36)$. Both populations only engaged in predator inspection once the red rainbowfish was visible (mean rate: 4.2 inspections/trial), however, predator inspection frequency did not significantly differ between populations ( $t$ test, $t 30$ $=1.52, \mathrm{P}=0.14)$.

\subsection{Correlations between anti-predator behaviours}

We found no significant correlations between the difference scores for shoaling, predator inspection and freezing in either domestic or feral guppies (Pearson's correlations, $-0.39 \leq \mathrm{r} \leq 0.19, \mathrm{~N}=14-17$, all $\mathrm{P} \geq 0.17$ ).

\section{Discussion}

Both feral and domestic guppies increased their shoaling behaviour and engaged in predator inspection when a novel predator was revealed, and both were sensitive to alarm substance. Feral guppies shoaled more than domestic guppies, both before and after exposure to a novel predator, but the populations did not signifi- cantly differ in predator inspection, responses to alarm substance 
or in exploration and boldness. There was no evidence that the anti-predator responses formed a suite of coupled behaviours.

Predation levels have been strongly implicated in population differences in shoaling among wild guppies (Magurran, 2005), and adaptation to predation at Burgers' Zoo may have driven the shoaling phenotype in the feral guppies. Predators have been shown to target individuals within a group that exhibit less cohesive grouping behaviour (Ioannou et al., 2012; Quinn and Cresswell, 2006); and thus prey selection by predators would be expected to increase the population-level shoaling phenotype over time. We did not find evidence for covariance of the different anti-predator behaviours we measured, a result that suggests anti-predator behaviours were uncoupled, and that shoaling was the most labile of the behaviours we tested, perhaps because it carries the most significant costs and benefits. The different anti-predator behaviours may be independently responsive, reflecting differences in the adaptive value of each behaviour depending on the specific predator threat. Alternatively, the uncoupling may reflect limits on the variation that can emerge, for example as a result of differences in allelic diversity at loci which regulate each behaviour. Larger sample sizes may have helped reveal differences in the other behaviours measured, however, predation effects on guppy behaviours are not always consistent (Brown et al., 2009; Seghers and Magurran, 1995) indicating that other factors can have an influence.

We used an allopatric fish predator to allow us to test the responses of both populations to a novel predator, and sensitivity to predators was evident in both feral and domestic guppies' shoaling, predator inspection behaviour and alarm substance responses. Many generations of domestication and artificial selection has thus not eliminated predator sensitivity in domestic guppies and this may help to explain the success of introduced guppies despite novel local allopatric predators (Deacon et al., 2011). Predationlinked behaviours have previously been implicated in the success or failure of species introductions (Holway and Suarez, 1999) and other invasive poeciliid species show elevated anti-predator behaviour compared to non-invasive species (Rehage et al., 2005). Our finding that anti-predator responses are maintained despite domestication 
has implications for captive breeding and reintroduction programmes for endangered fish (see e.g. Brown and Day (2002)).

We cannot discount the possibility that aspects other than predation may have shaped the feral phenotype as our study compared only two populations, and additional feral populations would clearly be essential to eliminate alternative explanations for our results (Dingemanse et al., 2009; MacLean et al., 2012; Reader and Hrotic, 2012). While both the feral and the domestic populations were originally derived from mixed domestic strains, making it unlikely that phenotypic differences were due to differential levels of inbreeding, they are not derived from the same source populations and so founder effects cannot be discounted. We also considered other environmental influences, however, differences in food availability between domestic and feral guppies are unlikely to have been a factor as feral guppies are able to feed ad libitum due to the manatees' feeding regime. While the manatee pool is constantly filtered and tested and water quality resembles that of an aquarium, guppy ectoparasites, such as Gyrodactylus spp., are present at low levels. However, the feral guppies were treated to remove parasites after capture, four months prior to the study. Moreover, any direct effects of surviving parasites would be predicted to result in reduced shoaling, as infected individuals are avoided within shoals (Croft et al., 2011), andGyrodactylus infection reduces shoal cohesion (Hockley et al., 2014). Residual developmental or evolutionary effects of Gyrodactylus presence are also unlikely to explain the observed shoaling phenotype, because these ectoparasites are transmitted socially. Consequently, a population history of Gyrodactylus infection would be predicted to lead to reduced grouping as an adaptation to avoid infection.

Caution should be taken when drawing conclusions about adaptation from two-population studies, such as our own, since any two populations are likely to differ on numerous characteristics, not just the factor proposed to favour adaptation. However, comparisons of two populations or species is a commonly used approach, and one that has made many useful contributions (Dingemanse et al., 2009; Reader, 2014). Such comparisons can provide a starting point, demonstrating population differences that suggest plausible hypotheses for 
further work. They are particularly valuable when experimental manipulation of the proposed causal variable presents ethical or logistical problems. The specific circumstances of the Burgers' zoo population provides an independent and rare opportunity to examine 20 years of guppy evolution in wellcharacterised and semi-controlled feral conditions. The general background of the introduced fish is known, and the zoo environment affords a relatively stable environment with minimal variation in factors such as water quality, temperature, or food availability that can vary extensively in most feral or wild environments, often varying together with predation regime (Magurran 2005). The above considerations, in combination with previous work on predation and shoaling tendencies (Huizinga et al., 2009; Magurran, 199ob; Magurran and Seghers, 1991), suggest that 20 years of predation in a feral environment is the most likely explanation for the observed increase in shoaling behaviour in these guppies. Despite years of artificial selection, ornamental fish such as domestic guppies retain both behavioural sensitivity to predator threats and the capacity to adapt to these. 


\section{Acknowledgements}

This work was supported by Utrecht University's 'High Potential' and 'Stimulus Fund' programmes, the Netherlands Organisation for Scientific Research (NWO) 'Evolution and Behaviour' programme, and the Lucie Burgers Foundation for Comparative Behaviour Research, Arnhem, The Netherlands. We thank Henk Schriek, Ko van Rootselaar and Cor Nijhoff for animal care assistance; Felipe Dargent and Lisa Jacquin for comments, and the administration of Burgers' Zoo and the Bush exhibit curator Max Janse for permission to study the feral guppies and for their generous advice and help. 


\section{$\underline{\text { References }}$}

Albers, P.C.H., 2000. Evidence for evolution of guppies in a semi-natural environment. Neth. J. Zool. 50, 425-433.

Brown, C., Day, R.L., 2002. The future of stock enhancements: lessons for hatchery practice from conservation biology. Fish Fish. 3, 79-94.

Brown, G.E., Godin, J.-G.J., 1999. Chemical alarm signals in wild Trinidadian guppies (Poecilia reticulata). Can. J. Zool. 77, 562-570.

Brown, G.E., Macnaughton, C.J., Elvidge, C.K., Ramnarine, I., Godin, J.-G.J., 2009. Provenance and threat-sensitive predator avoidance patterns in wild-caught Trinidadian guppies. Behav. Ecol. Sociobiol. 63, 699-706.

Croft, D.P., Edenbrow, M., Darden, S.K., Ramnarine, I.W., van Oosterhout, C., Cable, J., 2011. Effect of gyrodactylid ectoparasites on host behaviour and social network structure in guppies Poecilia reticulata. Behav. Ecol. Sociobiol. 65, 2219-2227.

Deacon, A.E., Ramnarine, I.W., Magurran, A.E., 2011. How reproductive ecology contributes to the spread of a globally invasive fish. PLoS One 6, e24416.

Dingemanse, N.J., Van der Plas, F., Wright, J., Réale, D., Schrama, M., Roff, D.A., Van der Zee, E., Barber, I., 2009. Individual experience and evolutionary history of predation affect expression of heritable variation in fish personality and morphology. Proc. R. Soc. London B: Biol. Sci. 276, 12851293.

Forslund, P., 1993. Vigilance in relation to brood size and predator abundance in the barnacle goose, Branta leucopsis. Anim. Behav. 45, 965-973.

Froese, R., Pauly, D., 2012. Fishbase. World Wide Web Electronic Publication, Version (10/2012) http://www.fishbase.org

Hass, C., Valenzuela, D., 2002. Anti-predator benefits of group living in whitenosed coatis (Nasua narica). Behav. Ecol. Sociobiol. 51, 570-578.

Hockley, F.A., Wilson, C.A.M.E., Graham, N., Cable, J., 2014. Combined effects of flow condition and parasitism on shoaling behaviour of female guppies Poecilia reticulata. Behav. Ecol. Sociobiol. 68, 1513-1520. 
Holway, D.A., Suarez, A.V., 1999. Animal behavior: an essential component of invasion biology. Trends Ecol. Evol. 14, 328-330.

Huizinga, M., Ghalambor, C.K., Reznick, D.N., 2009. The genetic and environmental basis of adaptive differences in shoaling behaviour among populations of Trinidadian guppies, Poecilia reticulata. J. Evol. Biol. 22, 1860-1866.

Huntingford, F.A., 2004. Implications of domestication and rearing conditions for the behaviour of cultivated fishes. J. Fish Biol. 65, 122-142 (Supplement A).

Ioannou, C.C., Guttal, V., Couzin, I.D., 2012. Predatory fish select for coordinated collective motion in virtual prey. Science $337,1212-1215$.

Krause, J., Ruxton, G.D., 2002. Living in Groups. Oxford University Press, Oxford, UK.

Lindholm, A.K., Breden, F., Alexander, H.J., Chan, W.-K., Thakurta, S.G., Brooks, R., 2005. Invasion success and genetic diversity of introduced populations of guppies Poecilia reticulata in Australia. Mol. Ecol. 14, 3671-3682.

Lung, M.A., Childress, M.J., 2006. The influence of conspecifics and predation risk on the vigilance of elk (Cervus elaphus) in Yellowstone National Park. Behav. Ecol. 18, 12-20.

MacLean, E.L., Matthews, L.J., Hare, B.A., Nunn, C.L., Anderson, R.C., Aureli, F., Brannon, E.M., Call, J., Drea, C.M., Emery, N.J., Haun, D.B., Herrmann, E., Jacobs, L.F., Platt, M.L., Rosati, A.G., Sandel, A.A., Schroepfer, K.K., Seed, A.M., Tan, J., van Schaik, C.P., Wobber, V., 2012. How does cognition evolve? Phylogenetic comparative psychology. Anim. Cogn. 15, 223-238.

Magurran, A.E., 1990a. The adaptive significance of schooling as an antipredator defense in fish. Ann. Zool. Fenn. 27, 51-66.

Magurran, A.E., 199ob. The inheritance and development of minnow antipredator behavior. Anim. Behav. 39, 834-842.

Magurran, A.E., 2005. Evolutionary Ecology: The Trinidadian Guppy. Oxford University Press, Oxford. 
Magurran, A.E., Seghers, B.H., 1990. Population differences in predator recognition and attack cone avoidance in the guppy Poecilia reticulata. Anim. Behav. 40, 443-452.

Magurran, A.E., Seghers, B.H., 1991. Variation in schooling and aggression amongst guppy (Poecilia reticulata) populations in Trinidad. Behaviour 118, 214-234.

Magurran, A.E., Seghers, B.H., 1994. Predator inspection behaviour covaries with schooling tendency amongst wild guppy, Poecilia reticulata, populations in Trinidad. Behaviour 128, 121-134.

Mathis, A., Chivers, D.P., Smith, R.J.F., 1996. Cultural transmission of predator recognition in fishes: intraspecific and interspecific learning. Anim. Behav. 51, 185-201.

Quinn, J.L., Cresswell, W., 2006. Testing domains of danger in the selfish herd: sparrowhawks target widely spaced redshanks in flocks. Proc. R. Soc. London B: Biol. Sci. 273, 2521-2526.

Reader, S.M., 2014. Evolution of cognition. In: Losos, J.B. (Ed.), Oxford Bibliographies in Evolutionary Biology. Oxford University Press, New York.

Reader, S.M., Hrotic, S.M., 2012. The limits of chimpanzee-human comparisons for understanding human cognition. Behav. Brain Sci. 35, 238-239.

Réale, D., Reader, S.M., Sol, D., McDougall, P.T., Dingemanse, N.J., 2007. Integrating animal temperament within ecology and evolution. Biol. Rev. $82,291-318$.

Rehage, J.S., Barnett, B.K., Sih, A., 2005. Behavioral responses to a novel predator and competitor of invasive mosquitofish and their non-invasive relatives (Gambusia sp.). Behav. Ecol. Sociobiol. 57, 256-266.

Reznick, D.N., Shaw, F.H., Rodd, F.H., Shaw, R.G., 1997. Evaluation of the rate of evolution in natural populations of guppies (Poecilia reticulata). Science 275, 1934-1937.

Seghers, B.H., 1974. Schooling behavior in the guppy (Poecilia reticulata): an evolutionary response to predation. Evolution 28, 486-489. 
Seghers, B.H., Magurran, A.E., 1995. Population differences in the schooling behavior of the Trinidad guppy, Poecilia reticulata - adaptation or constraint? Can. J. Zool. 73, 1100-1105. 
Fig. 1.
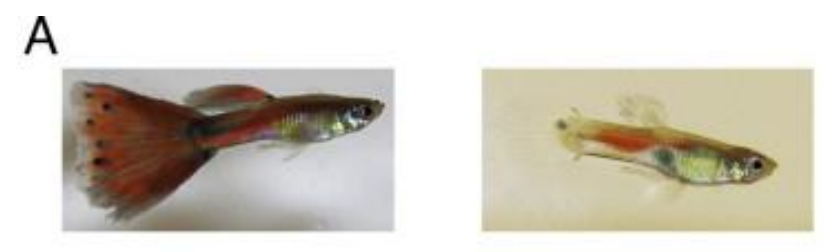

B
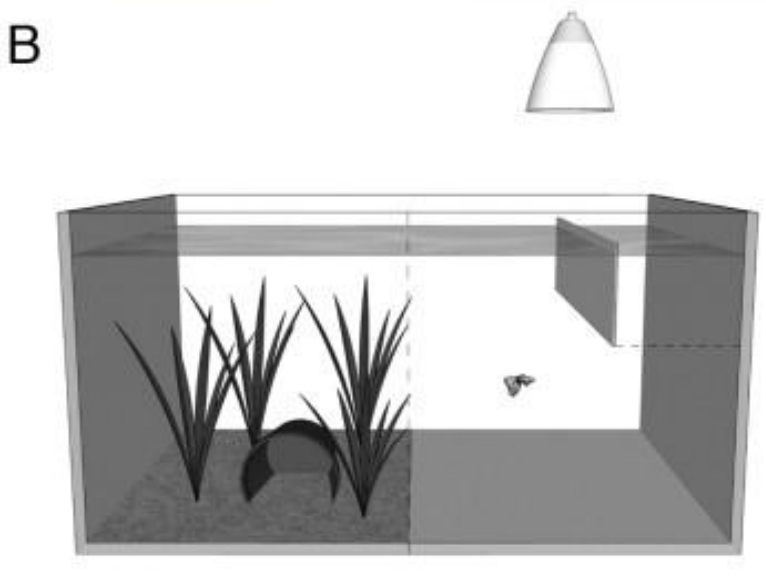

C 2

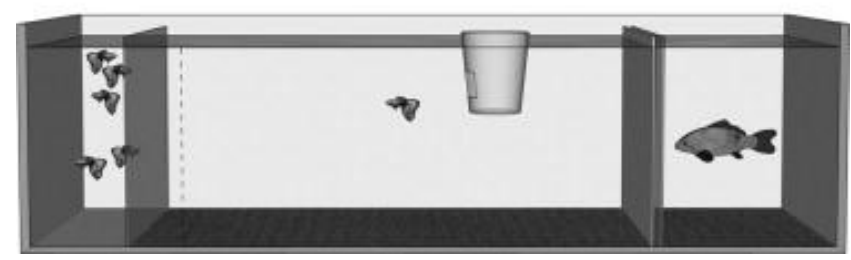

(A) Example photos of domestic (left) and feral (right) male guppies (W.T.

Swaney). (B) Sketch of boldness and exploration test apparatus. The $80 \mathrm{~cm} \times 50$ $\mathrm{cm} \times 40 \mathrm{~cm}$ tank comprised a sheltered area and a brightly lit exposed area containing the hidden area which subjects could not see into from their starting position in the sheltered area. (C) Sketch of shoaling and predator inspection test apparatus. The $90 \mathrm{~cm} \times 50 \mathrm{~cm} \times 25 \mathrm{~cm}$ tank was divided into a $10 \mathrm{~cm}$ wide shoal section (left), a $20 \mathrm{~cm}$ wide predator section (right) and a subject section (centre) containing the cups from which subjects started. 
Fig. 2.
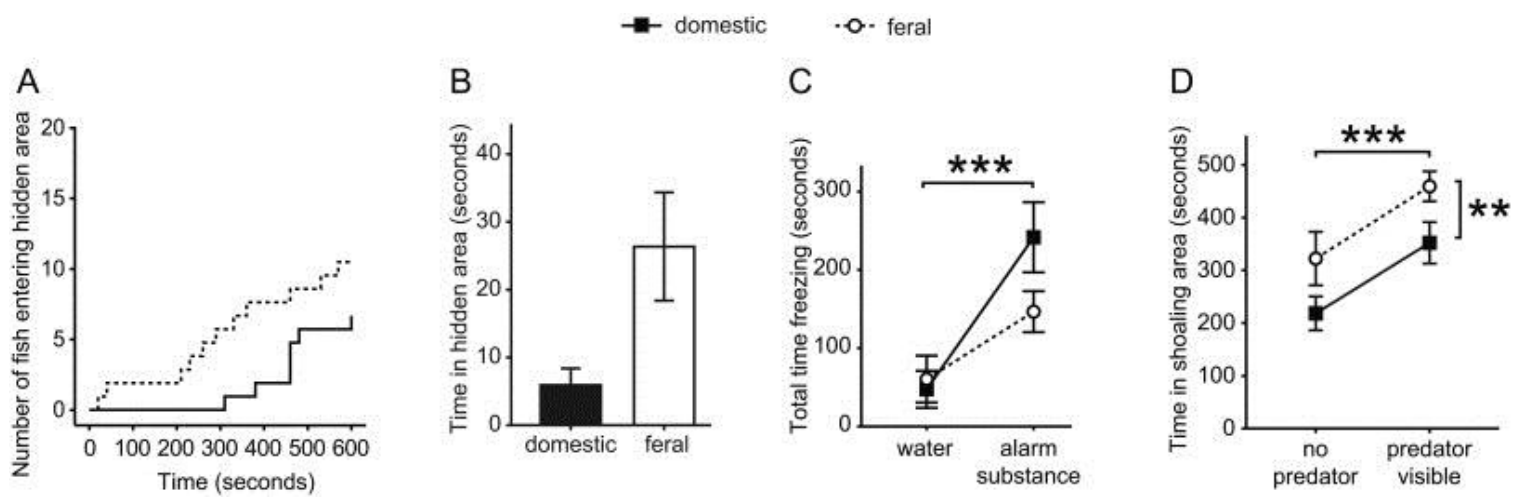

(A) Cumulative timeline of subjects' latency to reach the hidden area and (B) total time in the hidden area in exploration and boldness tests (feral $N=19$, domestic $N=19$ ). (C) Total time subjects spent frozen after addition of water and alarm substance in alarm substance tests (feral $N=17$, domestic $N=17$ ). (D) Total time subjects spent in proximity to the shoal in no predator and predator visible parts of shoaling and predator inspection tests (feral $N=15$, domestic $N=17)$. Data are means $\pm S E M,{ }^{* *}=P \leq 0.01$, ${ }^{* * *}=P \leq 0.001$. 